\title{
The Importance of Traditional Leafy Vegetables in South Africa
}
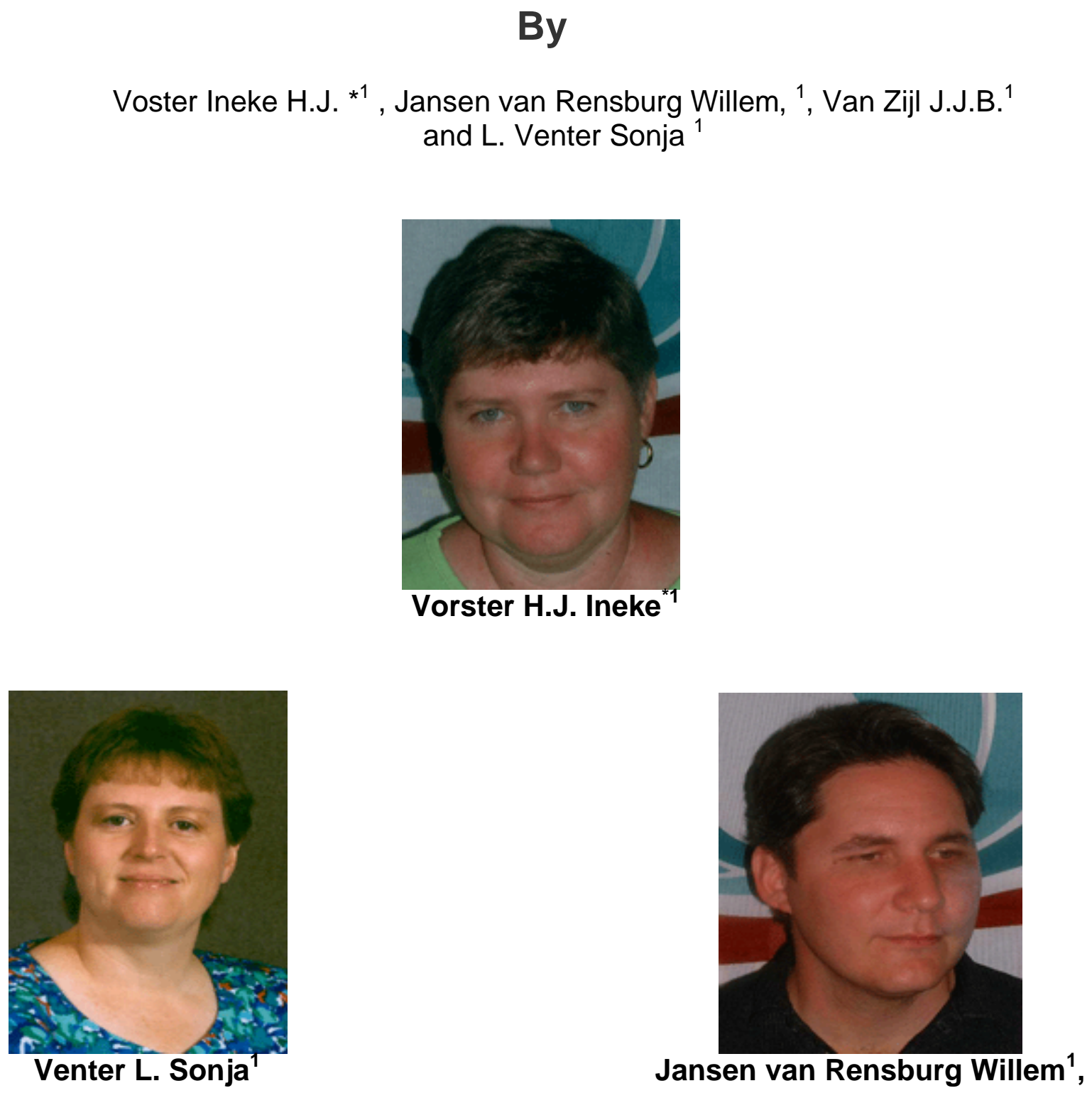

*Corresponding author Email: $\underline{\text { vvorster@ arc.agric.za }}$

${ }^{1}$ ARC-Roodeplaat Vegetable and Ornamental Plant Institute,Private Bag x293,Pretoria,0001, South Africa.Tel: + 27128419611 


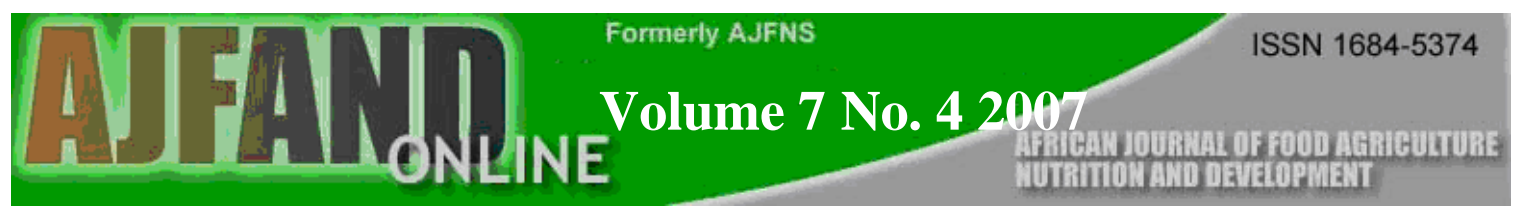

\section{ABSTRACT}

The use of traditional leafy vegetables in communities has been noted in several studies. These studies highlighted concerns about the loss of knowledge. The aim of this work was to enhance the role of African leafy vegetables in the nutrition of vulnerable groups in South Africa through improved preparation, promotion of consumption, processing, landrace improvement program, and management of their genetic diversity. Researchers needed to establish the extent of the use, conservation status and awareness of these plants, to ensure effective research decisions. The results from these studies are reported on here. Localities that differed in ethnicity and climate were targeted. The data collection phase used a questionnaire survey, rapid and participatory methodologies to collect information from the women. Traditional leafy vegetables were found to be a very important source of food in summer, but especially in winter. Several drying methods are used to ensure the availability of these vegetables during the winter. Pumpkins and cowpeas were the only crops grown, with some of the others occasionally broadcast. The most popular crops for consumption with all the age groups were amaranth and pumpkins, with jute mallow (Chorcorus sp.) and spider plant (Cleome gynandra) popular in the northern areas in South Africa. Where cowpeas were available, they were seen as the most valuable dried leaf product, as they were used as a safety crop due to their long shelf life. Ethnicity and gender had an effect on the use and preferences of the different crops, with men preferring the more bitter taste and women and children preferring the milder taste. Different ethnic groups showed differences in terms of bitterness of the taste and composition of the leaf mixes. In many areas seed systems were poor as the traditional role of keeper of the seed had been lost. Constant downgrading of traditional vegetables and associated knowledge by research and extension had led to the labels of 'backward knowledge' and 'poverty foods'. This led to a shift in food use and willingness of the youth to learn about and eat these crops. Awareness creation contributed to a change in the perceptions amongst the youth and adults, leading to increased demand for information and seed. It was determined that traditional leafy vegetables played an important role in food security in rural South Africa, but the status of the crops, as well as their conservation, need to be addressed to ensure sustainable use.

Keywords: Leafy vegetables, Food security, Conservation 


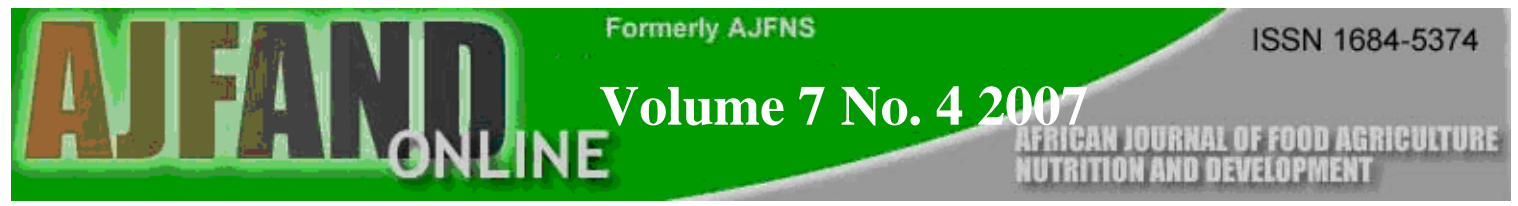

\section{INTRODUCTION}

Traditionally, agricultural research in South Africa was focused on large-scale commercial farmers and their mono-cropping systems. In the last decade, however, the focus has shifted towards the subsistence and semi-commercial farmers, but the work was still mainly based on the common commercial crops. Based on interactions between agro-ecological and socio-economic factors, the Brundtland Commission identified three types of agriculture: industrial agriculture, green revolution agriculture and resource-poor agriculture [1]. Most of subSaharan agriculture falls within the resource poor category characterized by marginal soils that are mainly rainfed. Resource-poor agriculture has complex farming systems and is risk prone, thus farmers employ diverse livelihood methods. South African farmers in the resource-poor group are mainly subsistence farmers who use a mixture of traditional and conventional practices.

The importance of indigenous knowledge and traditional crops in the survival strategies of rural people have only recently been recognized by research. The traditional leafy vegetables are still mostly treated as weeds by many research and extension personnel who criticize farmers for not keeping this weed population under control, thus labelling this important food as not worthy of the space it occupies.

Foods harvested from the veld can consist of different parts of the plant used. These can include roots, tubers, stems, rhizomes, leaves, flowers, fruits, nuts, gums, berries, cereals and legumes. In South Africa, local people formerly ate a diet of meat, milk, wild cereals and wild plants, but the Pedi proverb "Meat is a visitor, but morogo a daily food" (morogo are traditional leafy vegetables) has become a reality for most [2]. The use of traditional leafy vegetables in communities has been noted in several studies, with a countrywide study on foods from the veld being done from 1936 to 1982 . This study had highlighted their concerns about the loss of knowledge about these traditional food plants [2]. Since then studies on traditional vegetables have generally been small and localized. In an effort to enhance the role of African leafy vegetables in the nutrition of vulnerable groups in South Africa, research needed to establish the extent of the use, conservation status and awareness of these plants. The ultimate goal is to promote the use of African vegetables through improved preparation, promotion of consumption, processing, landrace improvement, and management of their genetic diversity by building on the indigenous knowledge and adding scientific technologies where necessary. This paper reflects on the use, preparation, processing, consumption, conservation and cultivation of the African vegetables. 


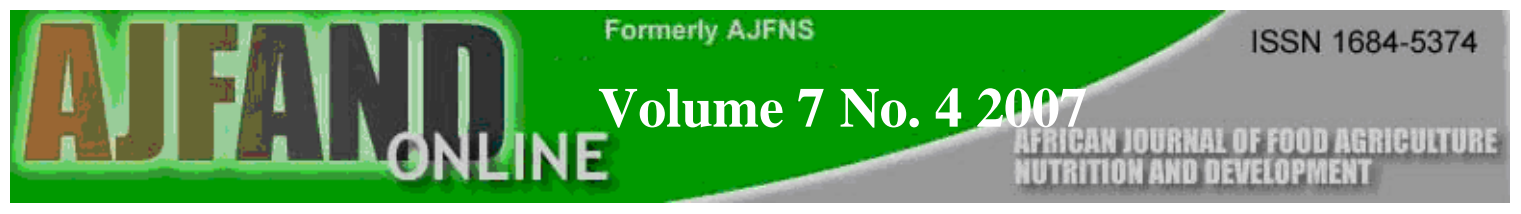

\section{MATERIALS AND METHODS}

\section{Choice of villages}

The work was done in seven villages in South Africa that differ in terms of ethnicity, geography and climate. Maps showing these different aspects were used to help identify the different villages, with areas where extension was active taking priority to ensure effective translation of the information. Diversity in the villages ensures as wide a range as possible in terms of uses and status of the traditional vegetables, thus being more representative of the diversity found within the country. The villages each represented a geographical area and an ethnic grouping. The villages were:

- Watershed, Ladysmith, KwaZulu-Natal: predominantly Zulu, close to the foothills of the Drakensberg with semi-arid conditions, summer rainfall, hot summers and bitterly cold winters (snows occasionally). Watershed's closest large town is about 45 minutes by taxi. There is no direct taxi service.

- Bushbuckridge, Limpopo Province: predominantly Shangaan, but five cultural groups are present. High summer rainfall, sub-tropical, mild winters, close to the Kruger National Park. Bushbuckridge is peri-urban, with supermarkets close by.

- Mars and Glenroy, near Polokwane, Limpopo Province: two neighbouring villages with predominantly Pedi people, semi-arid with hot summers, cold winters, low summer rainfall, mainly savannah type landscape. Mars and Glenroy's closest large town is about one hour away, no direct taxi service.

- Qunu, Umtata area, Eastern Cape (old Transkei): higher lying areas with hot summers and mild winters. Mainly summer rainfall. Dominated by the TembuXhosa. Qunu is about 30 minutes from a fresh produce market by taxi.

- Tshonya, Eastern Cape (old Transkei): predominantly Amapondo-Xhosa. Mainly summer rainfall, drier than Dimfi, very hot summers and mild winters. Tshonya is closer to a large town, about 45 minutes by taxi.

- Dimfi, Eastern Cape (old Transkei): predominantly Amapondo-Xhosa. Coastal, sub-tropical climate, year round rain (mainly summer), mild winters, hot and humid summers. Far from a big town. Dimfi is the last village on a dirt road that becomes impassable during rainy periods. It is poorly serviced by taxis and about 75 minutes from the closest large town.

\section{Data collection and analysis}

This paper combines two separate studies. The work done for the International Plant Genetic Resources (IPGRI) was done in Watershed, Bushbuckridge, Mars and Glenroy and concerned itself with African leafy vegetables. Data in all the areas were collected with participatory methods, with the IPGRI study also using

Published by Rural Outreach Program
KARI-NARL Complex, Westlands, off Waiyaki Way
P.O. Box 29086-00625 TEL: +254-20-4444030 FAX: +254-20-4444030
Nairobi, KENYA
Email: oniango@iconnect.co.ke OR info@ajfand.net www.ropkenya.org




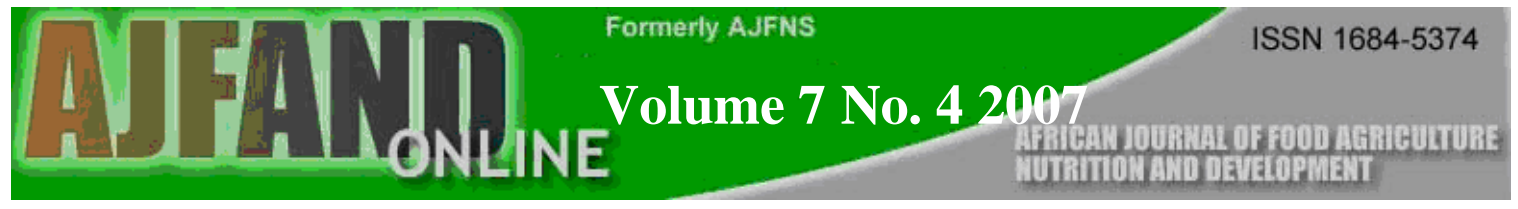

a questionnaire survey. A sample size of between $5-10 \%$ of the population (80 questionnaires per village) was used for the questionnaire survey, using a random sampling method. Some basic statistics were used with Excel to determine the descriptive variables. The tools from both rapid rural appraisal (RRA) and participatory rural appraisal (PRA) were used with the IPGRI and Agricultural Research Council (ARC) studies. As is appropriate with collecting indigenous knowledge, a number of specific questions were developed beforehand to ensure that information relevant to future indigenous vegetable research was generated and recorded [3]. The type of information needed determined the tools used, which included participatory mapping, direct matrix pair-wise ranking and scoring, seasonal calendars, direct observation, trend diagrams, semi-structured interviews, group interviews, local resource collection, shared presentation and analysis, self correcting field notes and intriguing practices and beliefs.

\section{RESULTS}

The results are reported in sub-sections, thus helping to understand the information better. Any percentages given are based on the IPGRI study in the four villages mentioned above.

\section{The communities}

In the IPGRI study areas in rural South Africa the average household size was between 6 and 7 people per household with every second home having a pensioner and each household having 3-4 children under 18 and 2-3 adults between 18 and 65. An average of 1.46 people contribute to a household income, of which most were household members working in the city and not included in the household size. Pensions (42.5\% of households) and formal labour (32.5\% of households) were the two most important sources of income for most families. The average monthly income of R774 (US\$112.3 at R6:1US\$) means that there is about US $\$ 0.57$ per person per day. Male headed households represented $45 \%$ of the households interviewed.

\section{Knowledge, status, preferences and plants used}

Knowledge of the different groups of plants was available from males and females. In all the villages the leafy vegetables tended to be the domain of the women only. Knowledge of fruit and cereals seemed to be in the male domain, with the children having only rudimentary knowledge of either and of traditional foods. The education of the children was blamed for the lack of knowledge, as small boys have to go to school and do not spend days in the veld looking after livestock and surviving on their knowledge of wild plants. The girls only tend to

Published by Rural Outreach Program
KARI-NARL Complex, Westlands, off Walyaki Way
P.O. Box 29086-00625 TEL; +254-20-4444030 FAX: +254-20-4444030
Nairobi, KENYA
Email: oniango@iconnect.co.ke OR info@ajfand.net www.ropkenya.org




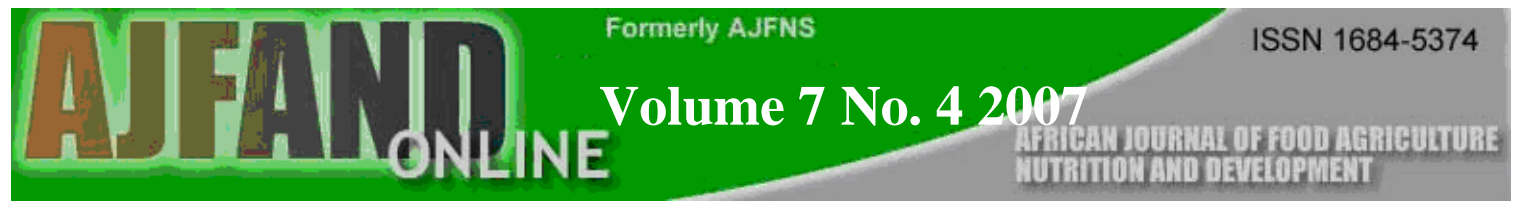

know the common and abundant traditional vegetables such as amaranth, cleome, cucurbits and grown vegetables (pumpkins, cowpeas, and so on) as they spend their days at school and have to do homework before dark. Women are the main cooks, and are sometimes supported by the girls in the family. 'Backward knowledge' and 'poverty foods' were labels linked to traditional vegetables and the associated knowledge, thus discouraging youth from learning about them.

The status of the leaves in the different gender and age groups varied with the different cultural groups. The Zulu, Shangaan, Swazi, Tsonga, Pedi and Ndebele groups tended to eat the leafy vegetables as a relish for the stiff porridge, and though not always preferred by men, was eaten by all. The Xhosa groups see leafy vegetables as a 'woman's food', and prefer to eat meat. The Xhosa mix the leaves into the stiff maize porridge and eat it as one dish. No gender differences were noted with the cucurbits, and the wide variety of cucurbits helped to increase the variety in taste. Pumpkins are planted by $98.3 \%$ of the households, making this an extremely important crop. Various types of cucurbits are planted, ranging from squashes to pumpkins and watermelons. All cucurbits are highly valued as they provide fruit, leaves and sometimes flowers for the diet. This makes the use of orange and yellow cucurbits very important in the alleviation of vitamin A malnutrition, given consumer preference for them.

The different areas tended to highlight the differences in cultural choice in terms of taste and plant choice. The most popular crops identified as the most important five crops listed by households for home use included amaranth (45.8\%) and pumpkins (96.7\%), with jute mallow (Chorcorus sp.) (44.4\%) and spider plant (Cleome gynandra) (64.4\%) popular in the areas where they grow. Where cowpeas (58.3\% listed in top five) are available, they are seen as the most valuable dried leaf product, as they are used as a safety crop due to their long shelf life. Balsam pear (Mimordica balsamina) was very popular (43.3\%) in the northern regions where it grows, with the leaves used when the plant is young and the older leaves used as a spice in the leaf mix. Ethnicity and gender had an effect on the use and preferences of the different crops. Generally men prefer the bitter taste of blackjack (Bidens pilosa L.), though they are used in the mix of leaves to help add taste to the dish. Cucurbits were highly valued in all regions. Amaranth was used in all the areas, with the Zulu using it mainly alone or as part of a mix of leaves. Spider plant is generally preferred to amaranth in the areas where it grows (the hotter northern parts of South Africa), with amaranth used as part of a mix of leaves. Lamb's quarters (Chenopodium album L.) is commonly used in the Eastern Cape, but is not so important in the northern regions. In each region individual crops were grown that were only used by a specific ethnic group. 


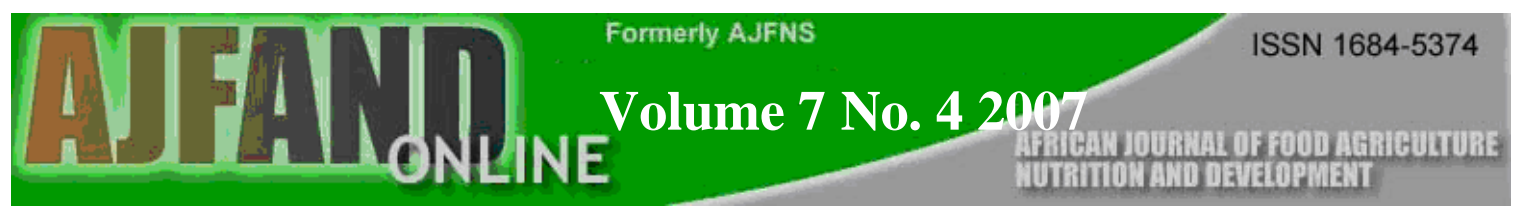

\section{Use fresh and dried}

Traditional leafy vegetables are a very important source of food in the summer, but especially in the winter. Food is very expensive in winter and the dried traditional vegetables form the basis of nutrition in most rural households, contributing up to about $80 \%$ of their total (excluding maize) food use in winter. Women try to add some other source of protein (usually in the form of chicken head and feet) once a week. Households with many members who do not supply an income tend to be more reliant on the traditional vegetables. This is especially true where unemployment is high and in the households where children no longer qualify for the child support grants. Most rural households know the importance of these foods in food security.

Several drying methods are used to ensure the availability of these leafy vegetables during the winter. In some areas of the Eastern Cape the knowledge of how to dry some of the different vegetables seems to have been lost. There is a feeling with the older people that it is possible that some of the information had been lost due to the high incidence of war and unrest (from 1960s to beginning of 1990s) in the area. This lack of drying knowledge is causing many problems in terms of food availability in the winter and spring months. Most of the leaves are dried in the sun, with the northern parts generally both blanching and not blanching, while the Xhosa's tend to dry without blanching. Shelf life of all the vegetables except cowpeas (Vigna ungucuilata L.) was felt as not satisfactory.

Access to a market had an influence on the use of traditional vegetables. In the IPGRI study area, $56.9 \%$ of total income was reportedly spent on food, with $67.8 \%$ of the women being able to decide how much is spent on food. A stronger reliance on TLVs was noted where transport was infrequent or expensive. Due to the social grants systems, family members have to go to town once a month, thus enabling them to buy supplies that keep well (oil, maize flour, sugar, etc.). Tinned foods are very expensive and fresh fruit and vegetables can only be kept for a short time.

This emphasizes the need for home grown foods when others are not available. The traditional vegetables are commonly looked upon as an additional source of food, due to its ability to grow in these generally marginal areas where low inputs and rain-fed conditions are common. Marketing of products fluctuate and is very limited. The women are the main marketers and this enables them to use the money made to pay for household necessities. The importance of this source of finances should not be underestimated, as it is used for health care, education, unexpected needs and food. 


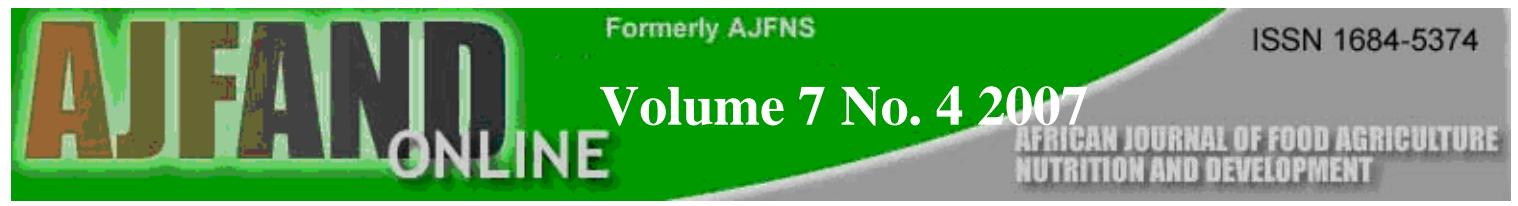

\section{Cultivation}

Cultivation of traditional vegetables is not very comprehensive, with the main reason for cultivation given as household food security. Only $40.8 \%$ of farmers growing TLVs do irrigate them, but mostly by hand. Further investigation showed that mainly pumpkins are irrigated, with the other crops growing under dry land conditions. About half of the fertilization done is in the form of cattle manure, with mainly composting and inorganic fertilizers contributing to the other half. Pumpkins are grown by $98.3 \%$ of the households interviewed, followed by cowpeas $(53.3 \%)$. Cowpea production information has been lost in many households. In Watershed, KwaZulu-Natal, the active NGO in the area had reintroduced the crop to the community on their request, after both seeds and production knowledge had been lost. Occasional broadcasting is done for balsam pear, watermelons, amaranth, spider plant and black jack.

\section{Conservation}

Discussions about the conservation status of TLVs had listed many concerns and explanations. The introduction of exotic vegetables ('good foods that you can buy in the shops') has had a negative effect on the use of TLVs in communities. The preferences of people have changed to the exotic vegetables and the use of fat in preparation methods has made it very popular with the young people. Drought and the rainfall pattern (heavy thunderstorms) had great impact on the availability of these plants. Drought led to over-harvesting of the plants, thus depleting seed banks. With the first thunderstorms (common rainfall pattern in most areas) the seeds are washed away due to the loss of topsoil and seed traps that can support growth. The bulk of TLVs used is made up of only a few different species, with many of the less used species becoming scarce or having been lost.

\section{Awareness of nutritional importance and general knowledge}

Awareness of importance of TLVs to nutrition is not very high; it is mainly perceived as being nutritious because the generations before them have survived on them. Traditional leafy vegetables have been labelled as 'poverty food', with the knowledge associated with it labelled as 'backward knowledge'. These labels have led to a shift in food use and less willingness of the youth to learn about and eat these crops.

\section{DISCUSSION}

The small percentage of people contributing to household income causes the household to be very vulnerable to outside influences. The World Health

Published by Rural Outreach Program
KARI-NARL Complex, Westlands, off Wailyaki Way
P.O. Box 29086-00625 TEL; +254-20-4444030 FAX: +254-20-4444030
Nairobi, KENYA
Email: oniango@iconnect.co.ke OR info@ajfand.net www.ropkenya.org




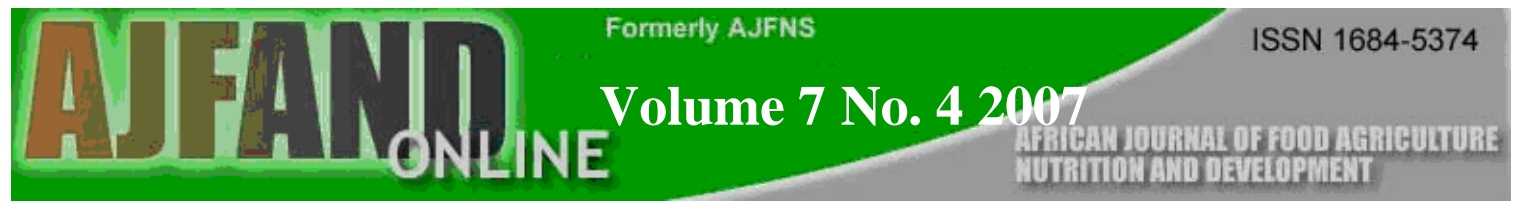

Organisation (WHO) HIV/AIDS statistics show increasingly more people in South Africa are affected by this pandemic [4]. AIDS has an impact on rural life as many people who live in the cities return to their rural areas when they become ill. The loss of a household member's labour due to HIV/AIDS related illness and death or even the loss of labour due to caring for afflicted household members affects the household in a number of ways. The illness often leads to loss of household labour supply as someone needs to care for the ill person, resulting in the spread of the activities between the remaining household members who are already involved in other livelihood activities. In cases where the ill person had sent remittances home, this income would also be lost to the family [5]. The implication is that many households will not be able to carry out all of the existing or increased number of tasks, or at least not without making considerable sacrifices in other livelihoods. WHO November 2005 figures show that $29 \%$ of pregnant women test positive, with the deaths since 1997 having doubled in the 25-44 age group. Since 1997 infection rates have grown with 62\% in the group of people older than 15 years. These statistics emphasize the value of crops that can be harvested with minimal inputs in terms of labour and finances.

Ethnic groups tended to prepare their traditional vegetables in only one way, and exposure to other preparation methods has enabled them to increase the variety in their diet. This would be an important step in increasing the popularity of the vegetables in the diet and needs to be addressed. The young find the preparation of the vegetables 'boring'. By handing out the recipes of different ethnic groups to women, their ability to vary the diet increases, and as these are prepared by people with the same type of resources, it makes it more accessible to them [6].

Drying of leafy vegetables helps to address the food shortages during the winter and spring when fresh food must be bought. Changing from mainly fresh to mostly dried products in the diet has debilitating effects on community members as diarrhea is common during the transition phase. Community members can ill afford this weakening of the immune system at a time when infectious diseases (flu, colds, TB) are very prevalent. Ways of planting some fresh produce during winter by using recycled water should be looked at.

In many areas seed systems are in a poor state as the role of keeper of the seed has been lost, leading to scarcity and even loss of some crops. The traditional role of keeper of the seeds in the communities has not been passed on and is part of the disintegration of the social systems in many rural areas. Revival of these roles within communities is critical in ensuring the availability of basic genetic diversity for future needs [7]. The loss of genetic diversity needs to be addressed, as genetic diversity supports food security and can provide security against pests, diseases and environmental conditions [8]. Almekinders and De

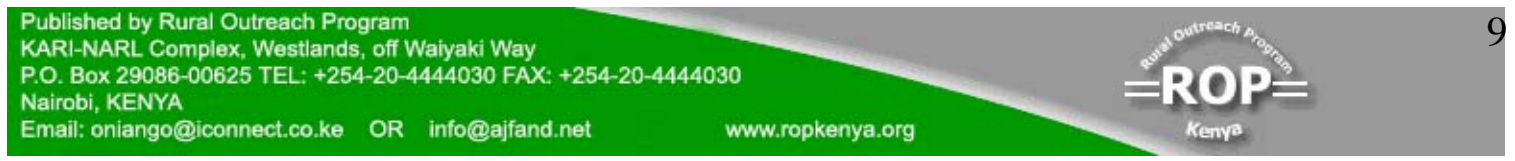




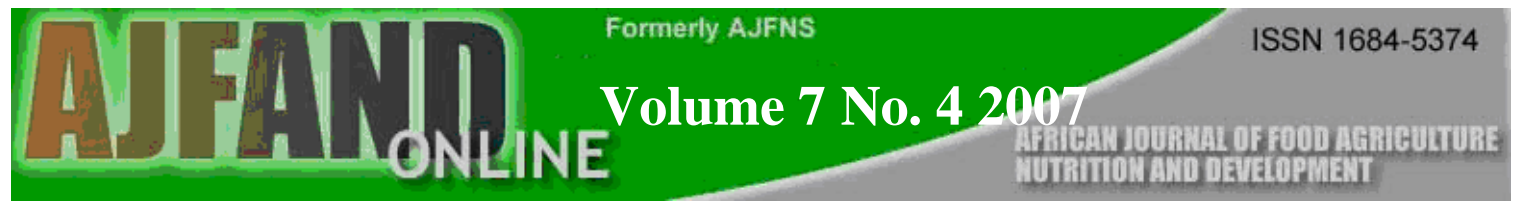

Boef stress that neither traditional nor improved varieties fully meet the farmers' needs [7]. The genetic diversity within communities is an important basis for future agricultural development in the world.

The labels of 'backward knowledge' and 'poverty food' led to the youth not being interested in these traditional crops. Where awareness of the value of these plants has been created, the youth interest also heightened [6], thus improving the status of the traditional plants and knowledge. Heightening the profile of traditional vegetables would help to improve the status of these 'poverty foods/ backward knowledge', thus making it more acceptable to the younger generation. The awareness raised contributed to a change in the perceptions amongst the school children and adults who had participated, leading to increased demand for information and seed. This is an important step that must not be ignored in areas where this kind of labelling has taken place and needs to be seen as a long-term action that should spread throughout South Africa.

\section{CONCLUSION}

Local peoples' indigenous agricultural knowledge plays an important role in achieving food security and conserving biological diversity [9] and can help increase the efficiency of development programs $[10,11]$. Development planning has often failed to achieve sustainable development and created dependencies due to erosion of indigenous knowledge (IK) about traditional vegetables and lack of awareness of benefits that the communities get by eating them.

Traditional leafy vegetables play an important role in food security in rural South Africa, and are usually not assessed for their influence on the livelihood strategies of rural people. The high unemployment rate in rural areas and the AIDS pandemic is placing huge demands on labour and food supplies, and there is an increasing need to make use of hardy, well adapted crops that need minimal labour and other inputs. With the dry spells, changing climate and marginal soils experienced by many poor, traditional vegetables might provide some relief. About half of children between 1-9 years of age consume less than $50 \%$ of the required vitamin A in South Africa [12]. This can be partly addressed by promoting the cultivation of these crops, as the pumpkins and amaranth are high in vitamin $\mathrm{A}$.

Promoting traditional vegetables to help diversify the food on the plate would help to create a larger market for these vegetables. To achieve this, the 'poverty food' label needs to be addressed. Placing these vegetables in the supermarkets would help to increase the status of the crops, as they are currently mainly being sold in informal markets. 


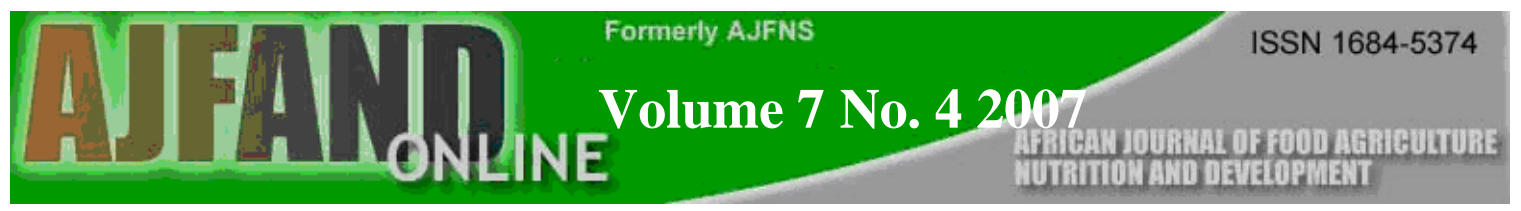

\section{RECOMMENDATIONS}

These hardy, adapted plants that tend to grow better than introduced crops in the marginal and dry areas should be further investigated. The following are some research needs that should be addressed: develop appropriate intercropping production techniques for the high yielding traditional crops to help increase food security in winter, evaluate the crops prepared or dried to help establish the most effective ways of preserving the nutritional content, developing a low-input crop rotation system that incorporates traditional and exotic crops in the local farming system.

Due to its poor status in most communities, knowledge of the crops is being lost at an alarming rate. Documentation and gene-bank actions need to have a high priority and should be combined with awareness activities in which the different aspects of traditional leafy vegetables are addressed. Awareness creation is a long term aspect that is commonly neglected, but this could have the effect of preserving a dead culture, causing leafy vegetables to become a curiosity crop. 


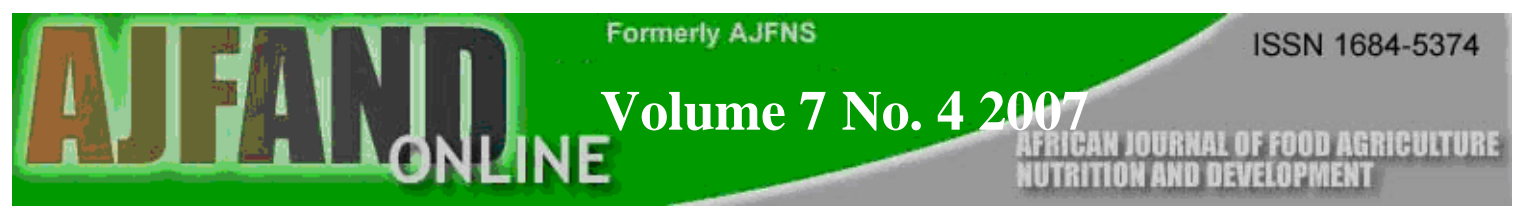

\section{REFERENCES}

1. World Commission on Environment and Development. Our Common Future, Report of the World Commission on Environment and Development .Oxford University Press, Oxford. 1987.

2. Fox FW and ME Norwood-Young Food From the Veld: Edible Wild Plants of Southern Africa. Delta Books, Johannesburg, South Africa. 1982.

3. Langill S Indigenous Knowledge: A Resource Kit for Sustainable Development Researchers in Dryland Africa. People, Land and Water Program Initiative, International Development Research Centre, Ottawa, Ontario, Canada. 1999.

4. World Health Organization www.who.int?hiv/FS_SubsaharanAfrica_Nov05_en.pdf accessed 25 November 2005.

5. Hunter LM and W Twine Adult Mortality and Household Dietary Use of the Local Environment: Qualitative Evidence from the Agincourt Field Site in Rural South Africa. Institute of Behavioral Science Working Paper EB2005-0001. Boulder: Research Program on Environment and Behavioral, University of Colarado at Boulder. 2005.

6. Vorster HJ, Van Rensburg WSJ, Mashele XB and E Ndlela The effect of (re)-creating awareness of traditional leafy vegetables on communities. Proceedings of the Indigenous Plant Use Forum Conference, Clanwilliam, South Africa, 5-8 July 2003. 2003.

7. Almekinders CJM and WS de Boef Institutional perspectives on participatory approaches to use and conservation of agro-biodiversity. In: Friis- Hansen E \& B Sthapit. Technical Bulletin on Participatory Approaches in use and conservation of Plant Genetic Resources. IPGRI, Rome. 2000, 2: 22-26.

8. Salazar $\mathbf{R}$ Community Plant Genetic Resources Management: Experiences in Southeast Asia. In: Cooper D, Vellvé R.and Hobbelink H (Eds.) Growing Diversity: Genetic Resources and Local Food Security. Intermediate Technology Publications, Exeter, 1992; 2: 17-29.

9. Warren DM Using Indigenous Knowledge in Agricultural Development. World Bank Discussion Papers no. 127. World Bank, Washington DC, USA. 1991. 


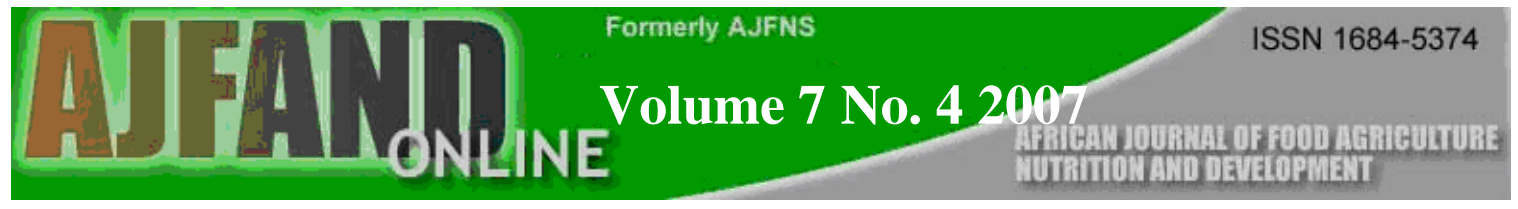

10. Grenier L Working with Indigenous Knowledge: A Guide for Researchers. IDRC, Canada, Ottawa. 1998.

11. Millat-e-Mustafa $\mathbf{M}$ Towards an understanding of indigenous knowledge. In: Sillitoe $P(E d)$. Indigenous Knowledge Development in Bangladesh: Present and Future. The University Press Limited, Dhaka, Bangladesh, 2000; 2: 27-30.

12. Faber $\mathbf{M}$, Laurie $\mathbf{S}$ and $\mathbf{S L}$ Venter Home-gardens to address vitamin $A$ deficiency in South Africa: A food-based approach. ARC-Roodeplaat, Pretoria, South Africa. 2006. 